\title{
Sign-symbolic system in the era of digital change
}

\author{
Elena Koltunova ${ }^{1 *}$, Galina Vlasova ${ }^{2,3}$, and Elisaveta Sagaidachnaya ${ }^{3}$ \\ ${ }^{1}$ State Educational Institution of the Rostov region, Rostov Regional Center for the Education of deaf \\ Students (SEIRR RRCEDS), 344022, Rostov-on-Don, Russia \\ ${ }^{2}$ Russian State University of Justice, Rostov Branch, 344000, Rostov-on-Don, Russia \\ ${ }^{3}$ Rostov State Economic University (RINH), 344002, Rostov-on-Don, Russia
}

\begin{abstract}
The article presents the analysis and generalizations, scientific justifications and views of scientists on the sign-symbolic system. Under this system, the "symbol" category and the "sign" category are separated. The sign is defined as a material definition, and the symbol is a treasure trove of meanings, since it has a unique ability not only to accumulate the age-old values of our predecessors, but also to form new semantic constructs through the disclosure of the contexts of ancient civilizations. This emphasizes the complementarity of the symbol and the sign, the interpenetration and ambiguity of their transition. Symbol possesses the power that can combine the perception of the world with the perception of the person him when understanding the meanings. The symbol is firmly embedded in the human consciousness and is the cultural and spiritual heritage of humanity. Its origin and stages of formation are inextricably linked and are considered in the context of a long evolutionary process with cultural changes in social life. A review of various theoretical concepts in the psychological and legal sciences on the problem of symbolism and symbolization allows us to reach a deeper, integrated level of its development and to understand the mechanisms and specific features of development.
\end{abstract}

\section{Introduction}

Symbolization is the process of creating (at the level of public consciousness) and mastering (at the level of individual consciousness) concepts-symbols that concentrate in a generalized form the significance of their specific properties as "super-important" or "super-real" [1]. The symbolization process is actively studied in psychological science $[2,3,4,5,6,7,8,9,10]$.

The origin of the symbol goes back centuries, at a time when primitive man came into contact with objective reality. Studying the thinking of ancient man, the first researchers (Fraser D. D., Taylor E. B.) came to the conclusion that the basis of the culture of that time was the animation of nature. "Everyone and everything is both the realities of the external world and the manifestations of the unified animation of nature, experienced as the movements of one's own soul" [11]. According to Levi-Bruhl, the spontaneous transfusion of meanings and states in this single psychophysical space is called "inclusiveness" or "participation" [12]. This is the origin of totems, taboos, marks(signs), myths as an empirical generalization, the basis of which is a subject - shaped component. Such "mythological

${ }^{*}$ Corresponding author: 4015821@gmail.com 
thinking" is a form of "bricolage" of Levi-Strauss [13], which creates a system of paradigms with fragments of the syntagmatic chain, leading to the emergence of new syntagms. In this regard, any product of creativity is a part of the dialogue with the "material" [14]. According to Davydova M. L., in the cultural aspect, the transition from the prehistoric to the human (that is, cultural) state means the beginning of the symbolic encoding of the world, a kind of doubling of reality [15]. It is impossible to identify a sign and a symbol, to bring them together. "A symbol is a certain sign structure that serves to denote an ideal content, different from its immediate objective existence, which opens up to the senses"[16]. F. De Saussure, Elmslev believe that a sign has a two-sided essence [17]. The sign acts as a certain form within which the symbol exists. The sign is given to denote an object, the function of the sign is auxilary, while the symbol is endowed with content. The sign is a material carrier, representing a different entity, carrying certain information [18]. Thus, when each person perceives a particular symbolic image, he or she invests in the content only its inherent new meaning. That is why it is impossible to call the symbols static. They are dynamic, deep, selfsufficient, inexhaustible, represent self-worth, constantly grow, acquiring versatility and fullness. This is because symbolic concepts have a function different from any other concept, since they act as universal indicators that orient the cognizing subject on the significance of the context, which should not just be perceived indifferently, but needs to be understood, evaluated and interpreted in a certain way [1]. In other words according to D. Chandler[14] this transformation follows definite stages: addition, deletion, substitution and transposition.

Each civilization has its own symbolic field. As it develops and changes, cultural and spiritual values are created, codes of conduct and laws are fixed. And, having arisen and become fixed in ancient mythology, symbolic images permeate the centuries, translating meanings, are perceived as interpersonal communication (text version), in which the encoded meanings are subject to decrystalization. A vivid proof of this is the image of Themis (or Justice) - the goddess of justice, whose symbolic content is very revealing. A symbol of justice, authenticity and objectivity of the law, the whole appearance and attributes of which emphasize the fairness of the legislative framework. The punishing sword in her hand is a symbol of mandatory, unconditional submission to the rule of law and accountability for crimes before the law, and the blindfold represents impartiality in sentencing. Libra - a kind of symbol of the measure of good and evil indicates a preponderance in a certain direction. This symbol is very ancient: it goes back to the weighing of souls in ancient Egypt.

The symbolism of the judicial process integrates different times, while there is a kind of alignment of the corresponding cultural prerequisites of justice. For example, in the same courtroom of the French court, there may be symbols of the era of absolute monarchy, the revolutionary republic, or the restoration.

The trial takes place as if under the supervision of its founding fathers. Such symbolism does not allow a contemporary to forget about the fundamental precepts that lie at the foundation of power, law, human freedom and society. For example, in the US Supreme Court, there is a rotunda full of busts of great legists, terrifying paintings, state symbols, murals on historical themes - all this reminds of the long path of democracy, the formation of freedom and civil society in the States. The statue of Lincoln allows his heirs to appeal to his authority. No collective space is conceivable without culture as a specifically symbolic way of organizing human existence, which provides it with its own symbol that expresses its values in the language of stone.

In fairness, it should be noted that the courthouses that are being built today are almost completely devoid of rich symbols (for example, the building of the European Court of Human Rights), the language of signs that are found in the old palaces of justice. Of course, modern structures made of glass and concrete are probably more functional and practical from an economic point of view. But then they are completely devoid of their specific cultural content and meaning (some, however, in the structures of their glass see the symbolization 
of the transparency of the court, its openness). However, this applies to all modern architecture. It should be noted that the hallmark of postmodernism is irony, whose incredible ability is to highlight a certain sign, giving it a special understanding. As Daniel Chandler $[14,124]$ noted after Levi-Strauss: «Irony is a marked form which foregrounds the signifier. Adolescents sometimes use it to suggest that they are sophisticated and not naïve. Limited use is usually intended as a form of humour. Frequent use may be associated with reflexiveness, detachment or scepticism. It sometimes marks a cynical stance which assumes that people never mean or do what they say. Sustained use may even reflect nihilism or relativism (nothing - or everything - is true). While irony has a long pedigree, its use has become one of the most characteristic features of postmodern texts and aesthetic practices. Where irony is used in one-to-one communication it is of course essential that it is understood as being ironic rather than literal». We are deeply convinced that comfort in its ultramodern sense, used in interior design, practicality, "long-lasting", etc. - is not a new style, but the absence of style at all. Maybe it is inevitable. But this leads to the destruction of the experience of subjectivity. The future is valuable, but only if the connection with the past is not lost. The connection is not in words, but as a constituent element of this very experience. After all, experience is always and only the boundary between the past and the future; it is possible as a correlation and experience of this difference.

What else can the symbolism of the trial, the palaces of justice say? In many palaces of justice in the countries of Western Europe, built before the First World War, a large number of images of violence are found: all sorts of impressive lion's mouths, various types of cold weapons, impaled bodies, fragments of battle scenes (real or drawn from most often the Old Testament or ancient mythology), etc. At first glance, such symbolism may even surprise: after all, the essence of the court, its functions are aimed at establishing a balance of sociocultural development, harmony of the individual and society. But the types of weapons and death scenes are not soft images that promote good feelings.

In reality, the violence depicted by the means of art (sculptures, bas-reliefs), on the contrary, is demonstrated and, to some extent, sublimated. According to Rene Girard, these images, which are difficult to fit in our minds, without doubt perform a compensatory role [19]. These rather cruel scenes of violence, lion's mouths, the spears piercing the bodies, not only inspire respect, but also set us free from aggression, recreating it inside us in a symbolic, euphemistic form. This symbolism in the palaces of justice in old Europe relieves a person from cruelty and sadism, it satisfies our hidden impulses, offering terrible images, but at the same time liberating from violence. According to Gerard, this symbolism indicates the genetic relationship of the trial with the sacrifice. Such symbolization is necessary, therefore, as the assimilation of socially dangerous, extreme forms of behavior in the cultural experience. The lack of authority turns into an excess of violence, an exit to the surface of the sacrificial principle.

Thus, the court, as a cultural institution, is the most important symbolic instance in society. It is impossible to do without it, especially in modern conditions of a general confusion of vectors of social development.

\section{Results}

The symbolic realm is the realm of the unconscious. For a more complete understanding of the symbolization process, we rely on the following basic directions:

I. Freud considered the suppression of libido and the production of the unconscious within the framework of a single phenomenon (individual unconscious). Studying the formation of the unconscious, he interpreted dreams as special characters (text) that replace the repressed conflicts and represent them in mind and in behavior [20]. 
II. K. Jung interpreted the pop-up fragmented or decorated in the plot of the series characters and their chains as historically accumulated experience of the generations that have a genetic component, and memory (the collective unconscious) [16].

III. A. Adler [21] identified the unconscious layer of the psyche and the emerging symbolic images with the manifestation of oppressed desires associated with certain personality traits: the desire to put pressure on other people, oppress them and lead over them, with an unfulfilled dream of power, with the presence of leadership traits that arise in addition to human awareness, involuntarily and considered the need for their research, study, decoding [22].

IV. E. Erickson studied the human essence in relation to culture from the point of view of the psychological principle, in which the theory of identity created by him is analyzed on the examples of ritual symbolization of homogeneous cultures, represented in the form of dreams that affect the choice of activities, the behavior of people, etc., where a state of trance was considered a dream, in the process of which symbolic images, pictures, perceived by people as life lessons, prescriptions or attitudes, in which the unconscious dominates over the conscious layers of the psyche [23].

V. In the understanding of E. Fromm, the nature of the symbolic traces the interpenetration of the social aspect of the structure of society and the psychotype of a person. The emergence of conflicts caused by the rejection of the "hostile" world, with the impossibility or difficulty of existing in the surrounding reality, defines a person, according to E. Fromm, as having own essence, core, pivot. And the influence of objectively existing situations on a person who has developed a certain stereotype of behavior, reaction to the vicissitudes of fate is understood by E. Fromm as the "second nature" of man, as his own inner culture, standing after the "first nature", biological. According to E. Fromm, violent reactions of a person to difficult life situations are involuntary, spontaneous and are recorded by him as a breakthrough of the unconscious in the corresponding moments of conscious existence [24].

T. Rabeyron, C. Massicotte believe that exists between the purely biological level and the subjective experience an ontic chiasm which specifies the differences between the processes of conscious psychic functioning. A Markov blanket operates as a space of delimitation and communication between these two levels in the sense that this blanket forms an organizational boundary which allows for the emergence of the subjective experience [5]. This idea is framed in Figure 1.

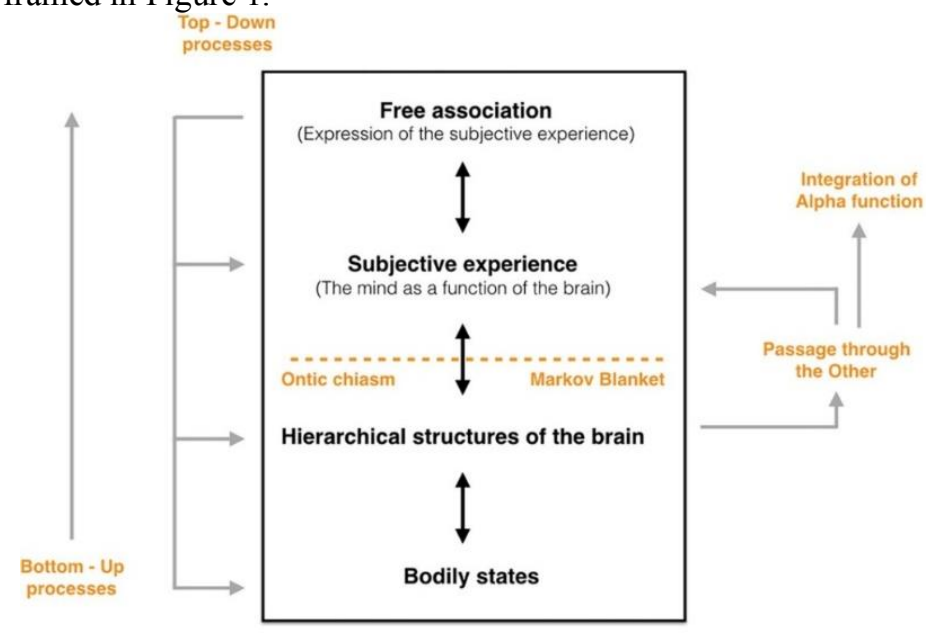

Fig. 1. Diagram proposes a synthesis of the passage from the (1) bodily states to (2) the hierarchical structures of the brain to (3) the subjective experience and to (4) the free association that expresses this experience. 


\section{Discussion}

Human life, in addition to reality, takes place in a symbolic space: in the world of designations, symbols, and signs. And the wider a person's horizons, the more sign-symbolic system helshe owns. L. S. Vygotsky emphasized that the sign organization is a complex-level system and is extremely important for the work of mental functions, the highest of which is speech [25]. Speech is an instrument of thinking, a means of communication and selfexpression, a means of cognition of the surrounding world. The word is originally a symbol, an ideal; the word condenses thoughts. This problem was studied by scientists from different countries: F. de Saussure, E. Benveniste, L. Elmslev, C. Ogden, A. Richardson, A. Gardiner, A. F. Losev, Yu.S. Stepanov and other scholars. Since the basis of the sign-symbolic system is activity, its result leads to the creation of a symbol as a means of mediating selfconsciousness [25]. As D. Chandler [14] metaphorically noted, this activity is associated with "creating home pages on the world Wide Web". Thanks to the structural-semiotic analysis, it is possible not only to describe a certain cultural system, but also to identify the meaning that "shines through this structure, revealing the "language" with which created information is given [26].

The symbol category is widely studied in jurisprudence. Interest in the legal symbol does not dry up. For example, I. K. Babaev characterizes the symbol as "a conditional image (a substitute sign) fixed by the legislation, used to express a certain legal content" [27]. According to the definition of P. D. Shalaginov, a legal symbol is a conditional sign of legal content created or authorized and protected by the state [28]. The understanding of a legal symbol by A.V. Nickitin is as follows: "a conditional image created or sanctioned by the state, a distinctive sign that represents a visible or audible cultural and value formation, to which the subject of law-making attaches a special political and legal meaning that is not related to the essence of this formation, protected by the state and used in a special procedural order" [29]. Thus, we observe that when interpreting a legal symbol, it is not fully exposed, only certain aspects of it are clarified. This is because the symbols are bottomless and intertwined with the experience of past generations and are embodied in one or another shell (form): the statue, marble, granite, as if they direct the course of consciousness of all beholders in the right direction and emphasize not the physical, but the ontological connection, while preserving and reproducing the sacred elements in the culture.

Legal symbols are attractive in their functional purpose. What are these functions? The symbols do not have a clear gradation in their functional purpose. Some scholar spoint out 3 functions: (preventive and indicative, strengthening the regulatory effect, saving the means of expression), whereas A.V. Nikitin has seven of them: regulatory, legal, informational, ideological, economic, protective and identification. The regulatory function is based on socially significant relationships. Their regulation is transmitted through actions by means of a symbolic form succinctly, clearly, colorfully, vividly, sometimes with a sound or visual effect according to the dictates fixed by law (a traffic light signal, a baton in the hands of a police officer, the lights of traffic signs, the sounds of motor ships and trains). The title function implies the presence of completeness on legal documents in the form of seals, facsimiles, and signatures. The informational function of legal symbols is to disseminate the necessary legal knowledge, updated regulations, acts, and contracts at various levels, including international ones. The symbols are accessible to all ethnic groups and unite people with different linguistic backgrounds. The ideological function consists in the emotional and psychological mood of people, about the activation of the ability of the symbol to convey to the masses the essence of the main elements of the ideology of the state and thereby unites with the symbols of normative and legal prescriptions (declarations) and consolidate the values of state power (medals, judicial accessories). Revealing the economic function, it should be noted that the symbols are so expressive, original, that linguistic and legal means 
are "curtailed", saved, because the symbol is able to embody and translate meanings. Therefore, the use of stamps, details, and printed forms brings order and a rational stream to the legal activity. The function of social and political - legal orientation is based on the generally accepted symbols and signs used, which help the individual to understand and comprehend the legal reality: in laws, in regulations, in documents, relying on familiar images, making it more accessible and harmonious to enter the legal field (system) into the established social life. The identification function of a legal symbol allows an individual not only to acquire legal knowledge, but also to distinguish him ไherself, to establish him $\backslash$ herself in the field of legal representations. The protective function of legal symbols is conditional, since the symbol can neither establish the measure of penalties nor determine responsibility for violations, but is more associated with regulatory acts. This group of symbols is able to provide evidence of protected objects or things and indicate (report) on (for) responsibility for what have been done. It is necessary to add the educational function of legal symbols. Being in society, each person is trained to observe the laws of the state and not to violate the established law and order. Through familiarity with legal symbols, people master the legal culture, become more literate and erudite.

\section{Conclusion}

The variety of symbols and signs creates a comprehensive and ubiquitous sign-symbolic system that emerged with the advent of life on Earth. As a cultural heritage, signs and symbols form a complex reality that conveys centuries-old accumulated experience, a created system of values, semantic guidelines, and establishes a link between generations. The legal symbol refers to the cultural riches of humanity. The symbolic system is able to transform the mental activity of the individual and his functions, to serve as a special tool for the formation of the value-semantic sphere and the development of personality in different age periods.

\section{References}

1. I.V. Abakumova, E.A. Koltunova, Symbol and symbolization: similarity and differences of interpretations in the context of various psychological approaches (CREDO, Moscow, 2013).

2. R. Mello, R. Herzog, Psicologia Clinica 28 (2), 15-28 (2016).

3. N. Cidade, S. Zornig, Psicologia USP 30, e180178 (2019). doi: 10.1590/01036564E 180178

4. T. Rabeyron, T. Loose, Frontiers in Psychology 6, 01926 (2015). doi: 10.3389/fpsyg.2015.01926

5. T. Rabeyron, C. Massicotte, Frontiers in Psychology 11, 366 (2020). doi: 10.3389/fpsyg.2020.00366

6. C. Boulay, C. Invernizzi, J. Lighezzolo-Alnot, N. Demogeot, Neuropsychiatrie de l'Enfance et de l'Adolescence 68 (8), 440-450 (2020). doi: 10.1016/j.neurenf.2020.10.004

7. N. Cidade, S. Zornig, Psicologia USP 30, e180178 (2019). doi: 10.1590/01036564E180178

8. R. Roussillon, Psyche 69 (5), 436-451 (2015).

9. S.M.A.-J. Zornig, Psicologia Clinica 27(2), 121-136 (2015). 
10. V.I., Abakumova, M.V. Godunov, A.V. Grishina, International Journal of Cognitive Research in Science, Engineering and Education 8 (2), 53-58 (2020). doi:10.5937/IJCRSEE2002053A

11. E.B. Taylor, A Collection of Short Stories (Create Space Independent Publishing Platform, 2011)

12. E.E. Pronina, Psychology of journalistic creativity (Knizhny dom universitet, Moscow, 2006)

13. K. Levi-Strauss, Primeval thinking (Respublika, Moscow, 1994).

14. D.Chandler, Semiotics: The Basics, Routledge Abingdon (Oxon OX14 4RN, 2002).

15. M.L. Davydova, Legal symbols and symbols in law: concept, meaning, classification (Nizhny Novgorod Academy of the Ministry of Internal Affairs of the Russian Federation, Nizhny Novgorod, 2008).

16. K.G. Jung, Introduction to Jungian Psychology: Notes of the Seminar on Analytical Psychology Given in 1925 (Princeton University Press, Princeton, 1997).

17. Saussure F. de Course in general Linguistics (S. Bally, A. Seshe of A. Riedlinger (Eds.). URSS, Moscow, 2016).

18. C.W. Morris, Foundations of the Theory of Signs (Chicago University Press, Chicago, 2009).

19. R. Jerar, Things Hidden From the Foundation of the World (Continuum International Publishing Group, 2004).

20. S. Freud, Introductory Lectures on Psychoanalysis (Digireads.com Publishing, 2013).

21. A. Adler, Individual Psychology (Piter, St. Petersburg, 2017).

22. I. V. Abakumova, E.A. Koltunova, Russian Psychological Journal 10 (4), 25-31 (2013). doi: $10.21702 /$ rpj.2013.4.3

23. E. Erikson, Childhood and society (Speech, St. Petersburg, 2000).

24. E.Fromm, Escape from Freedom (Holt Paperbacks, 1994).

25. L.S. Vygotsky, Psychology of development. Selected works (Yurayt, Moscow, 2019).

26. R.Jakobson, Selected Writings, vol. 2, Word and Language (The library of the University of California, Los Angeles, 2016)

27. V.K.Babaev, V.M. Baranov, General theory of law: a brief encyclopedia (Nizhny Novgorod, 1997).

28. P.D. Shalaginov, Functions of legal symbols (Dissertation abstract, Nizhny Novgorod, 2007).

29. A.V. Nikitin, Legal symbols (Dissertation abstract, Nizhny Novgorod, 1999). 